\title{
Unit of Molar Energy
}

National Cancer Institute

\section{Source}

National Cancer Institute. Unit of Molar Energy. NCI Thesaurus. Code C70444.

A unit used to express the amount of thermodynamic energy in one mole of substance. 